\title{
Validated analysis of HIF-1 $\alpha$ expression in cancer cells using a controlled and comparative immunoassay
}

\author{
MARIA IOANNOU ${ }^{1}$, ILIAS MYLONIS ${ }^{4,5}$, EVANGELOS KOUVARAS ${ }^{1}$, RODULA PAPAMICHALI ${ }^{1}$, \\ ALEXANDROS DAPONTE $^{2}$, EFROSYNI PARASKEVA ${ }^{3}$, GEORGE SIMOS ${ }^{4,5}$ and GEORGE K. KOUKOULIS ${ }^{1}$ \\ Departments of ${ }^{1}$ Pathology, ${ }^{2}$ Gynecology and Obstetrics, and ${ }^{3}$ Physiology, \\ ${ }^{4}$ Laboratory of Biochemistry, Medical School, University of Thessaly, Mezourlo, \\ 41110 Larissa; ${ }^{5}$ Institute of Biomedical Research and Technology (BIOMED), \\ 51 Papanastasiou Street, 41222 Larissa, Greece
}

Received September 18, 2009; Accepted November 3, 2009

DOI: 10.3892/or_00000841

\begin{abstract}
The immunoreactivity of hypoxia inducible factor $1 \alpha(\mathrm{HIF}-1 \alpha)$ has been considered a reliable indicator of the HIF-1 pathway activation in tissue hypoxia. However, HIF- $1 \alpha$ immunoreactivity has been evaluated with different antibodies and heterogeneous protocols. The need to interpret contradictory findings requires, among other things, a comparison of the antibodies. This could be accomplished by using identical, well characterized antigenic targets and by decreasing the influence of other variables. We applied most of the commercially available antibodies, and an antibody developed in our laboratories, to the human cervical cancer HeLa cell line and tissue sections from a renal cell carcinoma systematically, and to other tumors selectively. The expression of HIF-1 $\alpha$ in HeLa cells was induced by the hypoxia-mimetic DFO. Non-induced HeLa cells were used as 'genuine' negative controls in addition to routine ones. HeLa cells (both induced and not induced) were also examined by immunofluorescence and Western blotting. We found that the antibodies showed immunostaining patterns with remarkable qualitative and quantitative differences, an observation not emphasized in previous literature. Certain antibodies require careful application to avoid specificity issues, and others to avoid low sensitivity problems. Pairing certain antibodies can optimize evaluation of HIF- $1 \alpha$ expression. Most previous immunohistochemical studies of HIF-1 $\alpha$ have attempted to map hypoxic neoplastic tissues or to demonstrate hypoxia in studies of neoangiogenesis, rather than 'measuring' HIF-1 $\alpha$ expression or activation, because this requires a validated
\end{abstract}

Correspondence to: Dr Maria Ioannou, Department of Pathology, Medical School, University of Thessaly, 41110 Larissa, Greece E-mail: mioan@med.uth.gr

Key words: HIF-1 $\alpha$, immunohistochemistry, antibody, HeLa cells, carcinoma, hypoxia immunoassay. Our study thus allows for the development of a controlled and comparative HIF- $1 \alpha$ immunoassay, which could be valuable if HIF- $1 \alpha$ becomes a therapeutic target.

\section{Introduction}

HIF-1 $\alpha$ plays important roles in hypoxia-induced mechanisms for tumor survival, invasion and metastasis (1-3). Therefore, there is a significant number of studies on HIF-1 $\alpha$ expression (4-16).

HIF-1 $\alpha$ expression levels have been studied by different methods, including immunohistochemistry (17-27). Initially, the number of antibodies used was limited, but later on, most studies have been using several commercially available antibodies (28-50). HIF-1 $\alpha$ generally has been found to be overexpressed in tumors and to correlate with adverse prognoses; however, some inconsistent findings have been noted $(51,52)$.

Recently we have been involved in testing a new polyclonal anti-HIF-1 $\alpha$ reagent that we generated in our laboratories (53). During the process of evaluating this antiserum we had the opportunity to study the immunoreactivities of most commercially available anti-HIF- $1 \alpha$ antibodies in HIF$1 \alpha$-expressing (DFO-treated) and non-expressing (non-DFO treated) pelleted human cervical cancer HeLa cells. We used immunohistochemistry, immunofluorescence and Western blotting. To further evaluate HIF-1 $\alpha$ immunoexpression we also stained HeLa cells for BNIP-3 and VEGF, two wellknown targets of HIF-1 $\alpha$, which should be upregulated in DFO-treated cells. To compare the immunoreactivity patterns of different HIF-1 $\alpha$ antibodies we immunostained serial sections from a single renal cell carcinoma derived from a patient with von Hippel Lindau syndrome. In addition, we immunostained a variety of tumor types with the same panel of antibodies. We used image analysis to optimize the evaluation of staining. We present our findings, which show remarkable antibody-dependent variation of immunostaining. This comparison may help by highlighting certain issues on HIF- $1 \alpha$ immunoreactivity, and also by optimizing the selection of a HIF- $1 \alpha$ antibody panel for future studies. 


\section{Materials and methods}

Cell cultures and pellets. The human cervical epithelial cell line HeLa was maintained in Dulbecco's modified Eagle's medium (DMEM, High Glucose) (Gibco BRL), supplemented with $10 \%$ fetal bovine serum (Biochrom KG Seromed). Cells were incubated at $37^{\circ} \mathrm{C}$ in a humidified atmosphere containing $5 \% \mathrm{CO}_{2}$

HIF- $1 \alpha$ was induced by adding desferrioxamine (DFO) at final concentration of $150 \mu \mathrm{M}$. Then cells were collected, pelleted and fixed overnight in $4 \%$ buffered formalin. The cells were then dehydrated, cleared and processed to paraffin blocks, similarly to minute, routine, tissue samples in an automate tissue processor (Shandon Citadel 2000, ThermoElectron Corporation, UK). Sections, $3 \mu \mathrm{m}$ thick, were obtained for immunohistochemistry.

Tissue samples. Archival tumor samples were retrieved from the files of the Pathology Department of University of Thessaly. As selection criterion we used the previously described HIF-1 $\alpha$ immunoreactivity in surgical samples of similar morphology $(3,17)$. The types and numbers of these tissue samples are shown in Table I. A more detailed comparison of immunostaining was done in sections of one renal cell carcinoma and described in the Results.

Western blot analysis. After incubating HeLa cells for $4 \mathrm{~h}$ with DFO, cells were lysed in $20 \mathrm{mM}$ Tris-Cl, $150 \mathrm{mM} \mathrm{NaCl}$, $10 \%$ glycerol, $1 \%$ Triton X-100, 0.5\% ß-mercaptoethanol, $6 \mathrm{mM} \mathrm{MgCl}_{2}$ in the presence of a cocktail of protease inhibitors (pefabloc $1 \mathrm{mM}$, leupeptin $1 \mu \mathrm{M}$ and pepstatin $1 \mu \mathrm{M}$ ). Protein extracts $(40 \mu \mathrm{g})$ were resolved by $8 \%$ sodium dodecyl sulphate-polyacrylamide gel electrophoresis (SDS-PAGE) and transferred to nitrocellulose membranes according to standard protocols.

Western blots were analysed with five anti-HIF-1 $\alpha$ antibodies (Table II). Membranes were then incubated with horseradish peroxidase-conjugated anti-mouse IgG goat (1:3000; BioRad Laboratories, Hercules, CA, USA) or antirabbit IgG (1:3000, Cell Signaling, Beverly, MA, USA) and proteins were detected by enhanced chemiluminescence (ECL, Amersham).

Immunofluorescence microscopy. HeLa cells growing on glass slides were treated with $150 \mu \mathrm{M}$ DFO for $4 \mathrm{~h}$. They were then fixed with $3 \%$ formaldehyde and permeabilized with PBS containing $0.1 \%$ Triton X-100 for 15 min. After blocking non-specific binding with $3 \%$ bovine serum albumin (BSA) in PBS- $0.1 \%$ Tween-20 overnight, the cells were incubated for $1 \mathrm{~h}$ at room temperature with different antiHIF- $1 \alpha$ antibodies (Table II). Primary antibodies were detected by incubation with a fluorescein isothiocyanate (FITC)-conjugated rabbit anti-mouse secondary antibody (BioRad, 1:50 dilution in PBS containing 1\% BSA) and CY3-conjugated anti-rabbit secondary antibody (1:50 dilution in PBS containing 1\% BSA). After washing twice with PBS, cells were counterstained with 4',6-diamino-2phenilindole dihydrochloride (DAPI) for 2 min and mounted on slides. Images were collected on an Axioscope 40 Zeiss microscope.
Table I. Tumor samples immunostained with antibodies to HIF- $1 \alpha$.

Tumor type No. of samples

Renal cell carcinoma 5

Breast adenocarcinoma 5

Colon adenocarcinoma

Pancreatic adenocarcinoma 5

Gastric adenocarcinoma 3

Gallbladder adenocarcinoma 5

Pulmonary adenocarcinoma 5

Prostate adenocarcinoma 5

Ovarian adenocarcinoma 5

Endometrial adenocarcinoma 5

Pulmonary squamous cell carcinoma 5

Laryngeal squamous cell carcinoma 5

Urothelial carcinoma 5

Glioblastoma multiforme

\section{Immunohistochemistry}

HIF-1 1 . Immunostaining of HeLa cell pellets, tumor tissue samples and in serial sections of the same renal cell carcinoma was performed with all the monoclonal (MAbs) and polyclonal (PAbs) antibodies listed in Table II. The preparation of $3 \mu \mathrm{m}$ sections from HeLa cell pellets was described above. Prior to immunostaining, routine hematoxylin-eosin sections were examined in order to verify the optimal preservation of HeLa cells.

The tissue samples had been fixed in $10 \%$ buffered formalin, processed and routinely embedded in paraffin. Sections were cut at $3 \mu \mathrm{m}$ using a Leica TP1020 microtome and dried overnight at $60^{\circ} \mathrm{C}$. After deparaffinization in xylene, the sections were rehydrated in decreasing ethanol solutions.

Different methods of antigen retrieval were tested in pilot experiments (data not shown). Under the conditions of the study, optimal antigen retrieval was achieved by microwaving all sections in $0.01 \mathrm{M}$ citrate buffer solution ( $\mathrm{pH}$ 6.0) for $20 \mathrm{~min}$, (LG WAVEDOM, $850 \mathrm{~W}$ ). This antigen retrieval remained optimal independently of the type of the primary antibody. Given this preliminary observation and the need to decrease the number of variables affecting immunoreactivity in antibody comparison, we used uniformly the aforementioned antigen retrieval method.

After the antigen retrieval, the sections were cooled and then they were washed in phosphate-buffered saline (PBS) for three times. Then they were incubated in $0.3 \%$ hydrogen peroxide for $10 \mathrm{~min}$, to block endogenous peroxidase.

Tissue sections and sections from pelleted cell blocks were incubated overnight at $4{ }^{\circ} \mathrm{C}$ with each antibody. The optimal dilutions were determined by trial and error (Table II). Then, the slides were washed in PBS and Envision fluid (polymerperoxidase method, EnVision+/HRP, Dako, Carpinteria CA, USA) was added, followed by incubation for $30 \mathrm{~min}$. Bound antibodies were visualized by using $0.05 \%$ 3,3'-diaminobenzidine solution (DAB, Dako). Finally, 
Table II. Antibodies to HIF-1 $\alpha$ used in this study.

\begin{tabular}{|c|c|c|c|}
\hline Antibody & $\begin{array}{l}\text { Optimal } \\
\text { dilution }^{\mathrm{a}}\end{array}$ & $\begin{array}{l}\text { Range of } \\
\text { dilution }^{\mathrm{a}}\end{array}$ & Source \\
\hline MAb1 (H1a67 aa 432-528, IgG2b) & $1: 25$ & $1: 100-1: 25$ & (NB100-105 ) Novus Biologicals, Littleton, CO \\
\hline MAb2 (H1a67, aa 432-528, IgG2b) & $1: 25$ & $1: 700-1: 25$ & (NB100-123) Novus Biologicals, Littleton, CO \\
\hline MAb3 (H1a67, aa 432-528, IgG2b) & $1: 200$ & $1: 1000-1: 100$ & Abcam, Cambridge, UK \\
\hline MAb4 (H1a67, aa 530-826, IgG1) & $1: 75$ & $1: 200-1: 50$ & $\begin{array}{l}\text { Neomarkers, LabVision Corporation Thermo } \\
\text { Scientific, UK }\end{array}$ \\
\hline MAb5 (54/HIF-1 $\alpha$, aa 610-727, IgG1) & $1: 20$ & $1: 500-1: 20$ & BD Transduction Laboratories, San Diego, CA \\
\hline MAb6 (HIF-1 $\alpha$ aa 329-530 IgG2a) & $1: 800$ & $1: 1500-1: 800$ & Sressgen, USA \\
\hline PAb1 (Rabbit polyclonal, aa 575-780) & $1: 200$ & $1: 1000-1: 100$ & Santa Cruz Biotechnology, Santa Cruz, CA \\
\hline PAb2 (Rabbit polyclonal ${ }^{\mathrm{b}}$, aa $\left.348-826\right)$ & $1: 200$ & $1: 500-1: 50$ & $\begin{array}{l}\text { Laboratory of Biochemistry, Medical School, } \\
\text { University of Thessaly }\end{array}$ \\
\hline
\end{tabular}

${ }^{a}$ In preliminary pilot experiments we used HeLa pellets and a renal cell carcinoma previously known to express HIF-1 $\alpha$, in order to determine the optimal dilution of each antibody. This was done after optimizing the antigen unmasking method and after determining that overnight incubation would offer the best signal/noise ratio for this particular immunoassay. For each antibody we tested a range of dilutions and two observers blindly selected the 'optimal' one at a later time. ${ }^{\text {b}}$ This antibody was raised in rabbits using as antigen recombinant GST-HIF-1 $\alpha_{348-826}$ (53). For Western blotting of HeLa cells we used MAb3 (dilution 1:1000), MAb4 (dilution 1:500), MAb5 (dilution 1:500), PAb (dilution 1:500) and PAb2 (dilution 1:1000). For immunofluorescence of HeLa cells the dilution was 1:100 for each antibody used.

sections were counterstained with hematoxylin and mounted in DPX (BDH, UK). Negative controls were performed by omitting of the primary antibody and by substituting the primary anti-bodies with nonimmune sera. Sections from pelleted HeLa cell lines, not HIF- $1 \alpha$ induced, were also included as negative controls.

BNIP-3. Sections $(3 \mu \mathrm{m})$ from HeLa cell pellets were dried onto slides overnight at $60^{\circ} \mathrm{C}$. After deparaffinization in xylene and rehydration in decreasing ethanol solutions, slides were heated in $0.01 \mathrm{M}$ citrate buffer solution ( $\mathrm{pH}$ 6.0) for $10 \mathrm{~min}$ in a microwave oven. The sections were cooled, washed in PBS and incubated in $0.3 \%$ hydrogen peroxide in methanol for 15 min to block endogenous peroxidase. After washing with PBS, $75 \mu 1$ of blocking buffer (Dako) was added to each section for $1 \mathrm{~h}$. Then, the sections were incubated with the primary antibody (rabbit polyclonal antibody to BNIP3, Abcam, UK) at 1:75 dilution, overnight at $4^{\circ} \mathrm{C}$. After antibody incubation, slides were treated for $1 \mathrm{~h}$ with a secondary antibody, and the streptavidin-biotinperoxidase complex was added for $45 \mathrm{~min}$ (LSAB+systemHRP, Dako), following which 0.05\% 3,3'-diaminobenzidine (DAB) plus $\mathrm{H}_{2} \mathrm{O}_{2}$ was applied for 5 min to complete development. Finally, slides were counterstained with hematoxylin and mounted. For the negative control the incubation step with the primary antibody was omitted. Also sections from the pelleted non HIF-1 $\alpha$-induced HeLa cells considered as negative control.

$V E G F$. Sections $(3 \mu \mathrm{m})$ from HeLa cell pellets were dried onto slides overnight at $60^{\circ} \mathrm{C}$. After deparaffinization in xylene and rehydration in decreasing ethanol solutions, slides were heated in $1 \mathrm{mM}$ EDTA solution ( $\mathrm{pH} \mathrm{8.0)}$ for $2 \mathrm{~min}$ in a pressure cooker. The sections were cooled, washed in PBS and incubated in $0.3 \%$ hydrogen peroxide in methanol for $15 \mathrm{~min}$ to block endogenous peroxidase. After washing with PBS, sections were incubated with the primary antibody (clone JH121, Neomarkers, UK, dilution 1:50) for $1 \mathrm{~h}$ in room temperature. Then, the slides were washed in PBS and Envision fluid (polymer-peroxidase method, EnVision+/HRP) was added, followed by incubation for $30 \mathrm{~min}$. The slides were counterstained with hematoxylin and mounted. A hemangiosarcoma was used as positive control. A section in which the primary antibody was substituted with nonimmune mouse serum was used as negative control.

Image analysis. The public domain software for image analysis 'ImageJ for microscopy' (Rasband, W.S., ImageJ, US National Institutes of Health, Bethesda, MD, USA, http://rsb.info.nih.gov/ij/, 1997-2007) was utilized in order to dissociate the nuclear from the cytoplasmic immunostaining (54). The basic methodological steps are briefly mentioned in results regarding MAb3 and corresponding Fig. 4A. First, the color deconvolution plugin was applied in order to separate haematoxylin stain from the chromogen stain. Then, the k-means clustering plugin was performed for pixel-based segmentation of the RGB images with the antibody staining. Four class k-means segmentation was applied in order to discriminate specific nucleus staining. The threshold color plugin was used to filter out pixels that were of different staining intensity than the nucleus.

\section{Results}

Analysis of human cervical cancer HeLa cells. To evaluate the polyclonal anti-HIF- $1 \alpha$ antibody produced by our group 


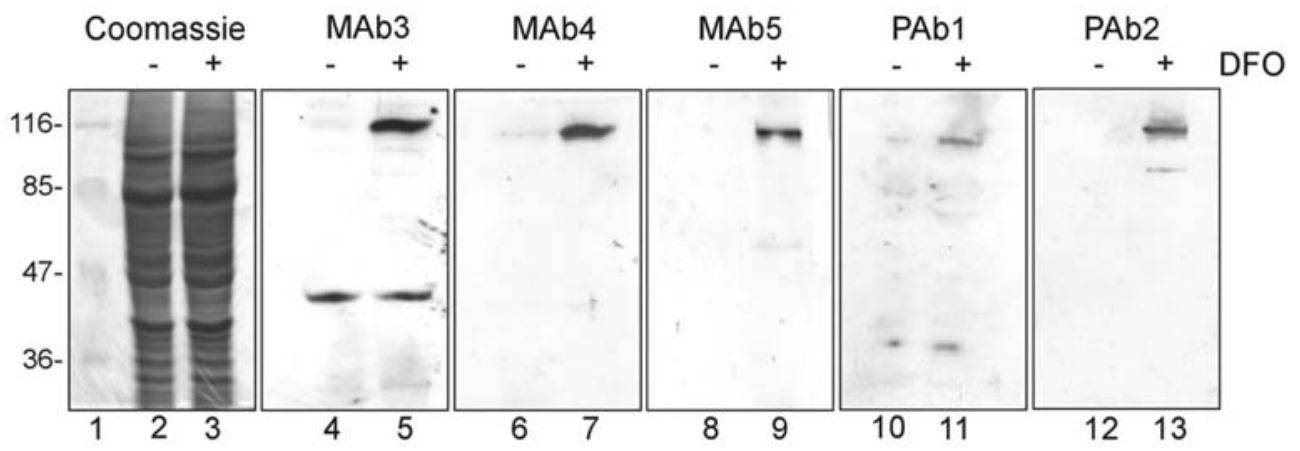

Figure 1. HeLa cells were treated without (-, lanes 2, 4, 6, 8, 10 and 12) or with (+, lanes 3, 5, 7, 9, 11 and 13) the HIF-1 $\alpha$ inducer DFO, lysed and analyzed by SDS-PAGE followed by Coomassie staining (lanes 2-3) or Western blotting (lanes 4-13) using the indicated antibodies. Lane 1, molecular weight markers.

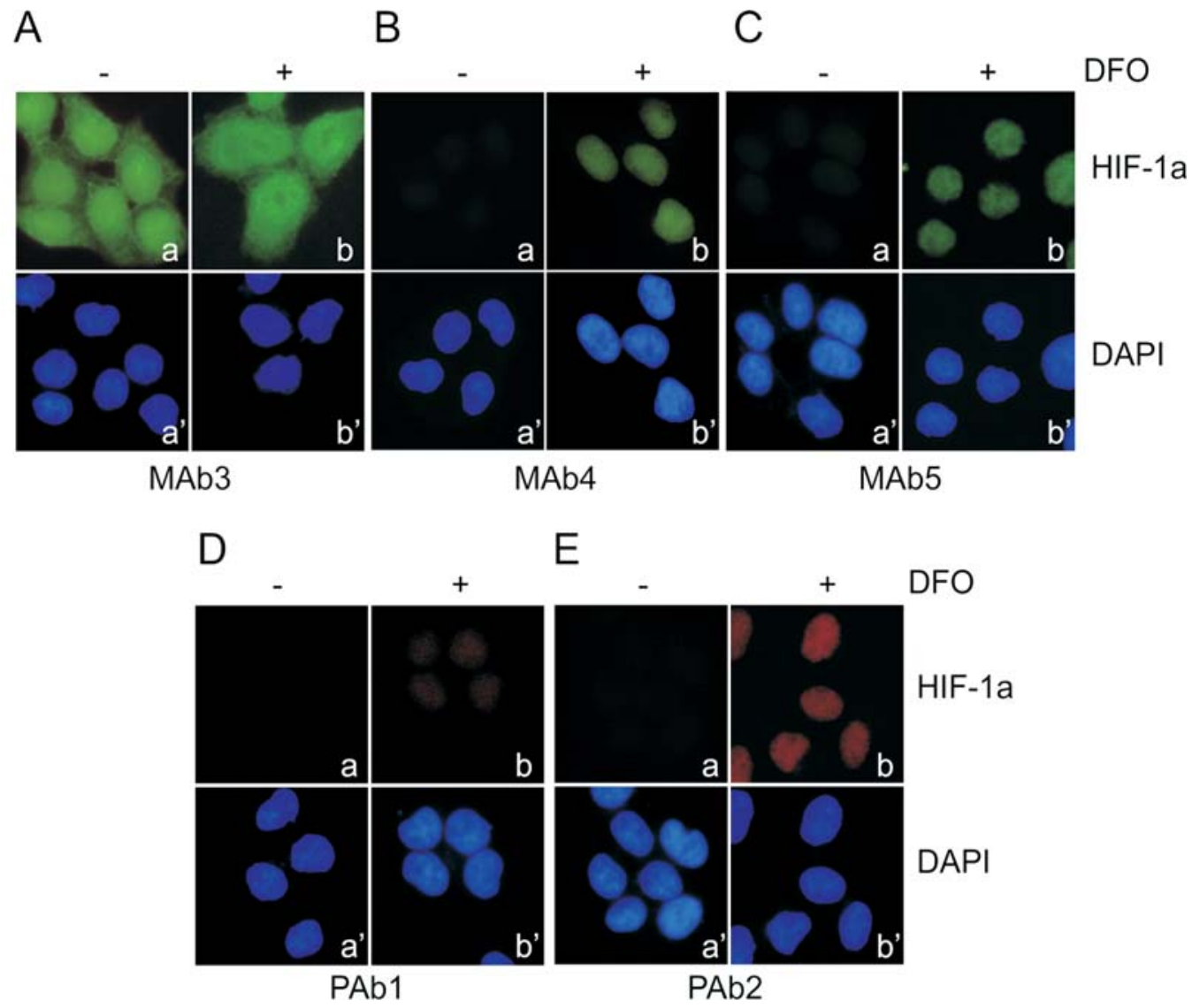

Figure 2. HeLa cells were treated without (-, a, a') or with (+, b, b') the HIF-1 $\alpha$ inducer DFO, fixed and analyzed by immunofluorescence microscopy using the following anti-HIF-1 $\alpha$ monoclonal antibodies (MAbs): MAb3 (A), MAb4 (B), MAb5 (C), and polyclonal antibodies (PAbs): PAb1 (D) and PAb2 (E). Nuclei were stained with DAPI.

and compare it to other widely used commercially available antibodies, we first analyzed total cell extracts from HeLa cells by Western blotting. Under normal conditions, subconfluent cultures of HeLa cells express very low to undetectable levels of HIF-1 $\alpha$. However, treating these cells with the hypoxiamimetic and iron-chelating agent DFO leads to stabilization and rapid accumulation of $\mathrm{HIF}-1 \alpha$, as well as stimulation of HIF-1 transcriptional activity (55). As shown in Fig. 1, our antibody (PAb2), as well as three monoclonal (MAb3-5) and one polyclonal (PAb1) commercial antibodies, readily detected HIF-1 $\alpha$ only in the DFO-induced cell extracts. However, the staining intensity and specificity varied. Of the three antibodies showing the highest specificity, MAb4 detected only full length HIF-1 $\alpha$ (Fig. 1, lane 7), and MAb5 and PAb2 also detected low molecular weight bands, which were absent from the non-induced samples and may, therefore, correspond to partial degradation products of HIF-1 $\alpha$ (lanes 9 and 13). MAb3 and, to a lesser degree, PAb1 (which was the weakest one) detected a low molecular weight band in both induced and non-induced samples, 
Table III. Immunoreactivity in HIF-1 $\alpha$ expressing and non-expressing HeLa cell lines.

\begin{tabular}{|c|c|c|c|c|c|c|c|c|}
\hline \multicolumn{5}{|c|}{ DFO-treated } & \multicolumn{4}{|c|}{ Non-DFO treated HeLa cells } \\
\hline Antibody & $\mathrm{NSe}$ & NSi & CytS & $\mathrm{NuS}$ & $\mathrm{NSe}$ & $\mathrm{NSi}$ & CytS & $\mathrm{NuS}$ \\
\hline MAb1 & Most nuclei & Intense & Present & Present & Not seen & Not seen & Present weak & Not seen \\
\hline MAb2 & Most nuclei & Intense & Present & Present & Not seen & Not seen & Present weak & Not seen \\
\hline MAb3 & Most nuclei & Intense & Present & $\begin{array}{l}\text { Present } \\
\text { intense }\end{array}$ & Rare nuclei & Weak & Present weak & Not seen \\
\hline MAb4 & Subset & Variable & Not seen & Not seen & Not seen & Not seen & Not seen & Not seen \\
\hline MAb5 & Subset & Variable & Not seen & Not seen & Not seen & Not seen & Not seen & Not seen \\
\hline MAb6 & Subset & Variable & Present & Not seen & Not seen & Not seen & Not seen & Not seen \\
\hline PAb1 & Most nuclei & Intense & Present & $\begin{array}{l}\text { Present } \\
\text { intense }\end{array}$ & Rare nuclei & Weak & Present weak & Strong \\
\hline PAb2 & Most & Intense & $\begin{array}{l}\text { Present } \\
\text { variable }\end{array}$ & Rare cells & Not seen & Not seen & Present weak & Not seen \\
\hline
\end{tabular}

Mab, monoclonal antibody; PAb, polyclonal antibody; NSe, nuclear staining extent; NSi, nuclear staining intensity; CytS, cytoplasmic staining; NuS, nucleolar staining.

suggesting their cross-reactivity with at least one more protein besides HIF- $1 \alpha$.

The same antibodies were also used to detect HIF-1 $\alpha$ in DFO-treated cells by immunofluorescent microscopy (Fig. 2). MAb4, MAb5 and PAb2 exhibited strong nuclear staining and undetectable cytoplasmic staining in DFO-induced HeLa cells (Fig. 2B, C and E), confirming that stabilized HIF-1 $\alpha$ accumulates efficiently inside the nucleus of these cells. In agreement with the Western blotting results, staining in the untreated cells by these antibodies was completely absent or barely detectable. Staining by PAb1 was weak but appeared specific, because only the nuclei of treated cells were labeled (Fig. 2D). Finally, MAb3 stained nuclei and cytoplasm of both DFO-treated and untreated cells (Fig. 2A), which is in accordance with the limited specificity exhibited by the same antibody in the Western blot experiments (Fig. 1, lanes 4 and 5).

These and three additional monoclonal antibodies (MAb1 and MAb2, which correspond to the same clone as MAb3 and Mab6) (Table II) were then used to immunohistochemically detect HIF- $1 \alpha$ in pelleted, formalin-fixed and paraffin-embedded DFO-induced or untreated HeLa cells.

Immunoreactivity patterns are summarized in Table III. Salient findings are depicted in Fig. 3. The following describes each probe's immunoreactivity: MAb1 and MAb2 stained the majority of the DFO induced HeLa cells (Fig. 3a and c). The nuclear staining was intense and there was also nucleolar staining. Cytoplasmic staining was detectable. The controls, non-DFO induced pelleted HeLa cells, showed very weak cytoplasmic staining. Nuclei and nucleoli were not stained in the non-induced controls (Fig. $3 b$ and d).

MAb3 stained the majority of the induced HeLa cells (Fig. 3e). The nuclear staining was intense and there was also nucleolar staining. Cytoplasmic staining was detectable. In some cells the presence of cytoplasmic staining made it difficult to assess the nuclear staining. The controls, non- induced HeLa cells, showed cytoplasmic staining weaker or similar to that of the hypoxic cells (Fig. 3f). In addition, there was a subset of cells with weak nuclear staining of unknown significance. Nucleoli were not stained in the non-induced controls. The assistance of image analysis confirmed the presence of 'genuine' nuclear staining (Fig. 4A).

MAb4 and MAb5 stained a subpopulation of the induced HeLa cells (Fig. $3 g$ and i). The nuclear staining was variable, being strong in some cells and weak in others. A significant number of cells (60-70\%) did not show nuclear staining. There was no nucleolar or cytoplasmic staining. The control noninduced HeLa cells did not show nuclear, nucleolar or cytoplasmic staining (Fig. 3h and j).

MAb6 stained a subpopulation of the DFO-induced HeLa cells. The intensity of the nuclear staining varied and there was no nucleolar or cytoplasmic staining (Fig. 3k). The control non-induced HeLa cells did not show nuclear, nucleolar or cytoplasmic staining (Fig. 31).

PAb1 stained almost all of the induced HeLa cells (Fig. $3 \mathrm{~m}$ ). The nuclear and cytoplasmic staining was intense. There was also strong nucleolar staining. In many cells the presence of cytoplasmic staining hindered the evaluation of nucleoplasmic immunoreactivity. In the control HeLa cells, cytoplasmic staining was detectable but was weaker than in the HIF-1 $\alpha$ induced cells. Rare cells also showed weak nucleoplasmic staining. Nucleolar staining was strong (Fig. 3n).

PAb2 stained almost all the induced HeLa cells (Fig. 3o). The nuclear staining showed slight variations. There was nucleolar staining and cytoplasmic staining was also detectable. In some cells the cytoplasmic staining showed a similar intensity to the nucleoplasmic staining; whereas in other cells the immunostaining was weaker in the cytoplasm than in the nucleoplasm. In the control HeLa cells, there was no nuclear or nucleolar staining. Cytoplasmic staining was rarely detectable and significantly weaker than that in the 

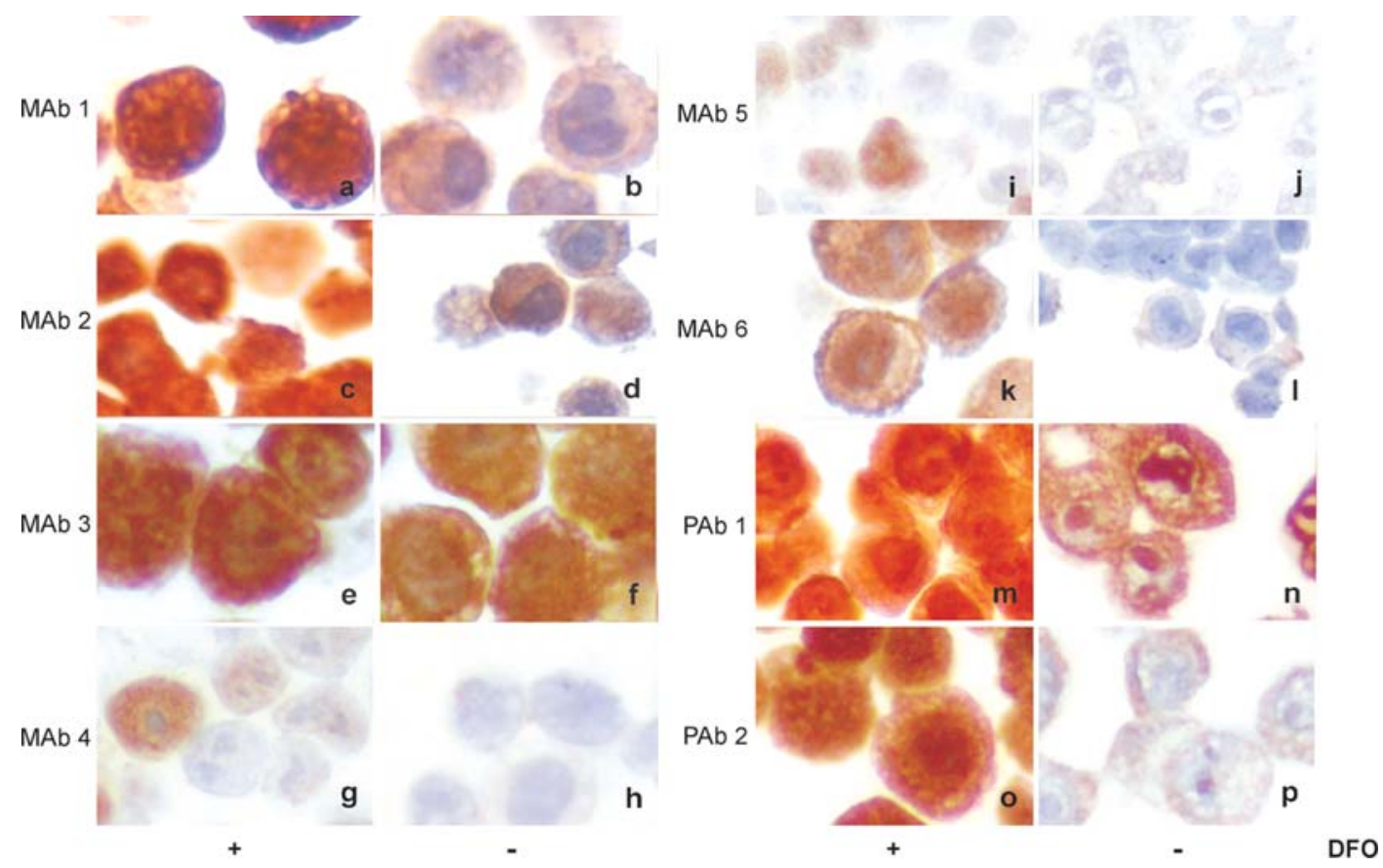

Figure 3. Immunostaining of HeLa cell pellets (DFO-induced a, c, e, g, i, k, m, o and not induced negative controls b, d, f, h, j, 1, n, p) with MAbs 1-6 and PAbs 1 and 2. MAb1, intense nuclear staining and detectable cytoplasmic staining in induced cells (a). MAb1, absent nuclear staining and weak cytoplasmic staining in negative control (b). MAb2, intense nuclear staining and present cytoplasmic staining in induced cells (c). MAb2, absent nuclear staining and weak cytoplasmic staining in negative control (d). MAb3, intense nuclear, nucleolar and cytoplasmic staining in induced cells (e). MAb3, nuclear staining is present in a few cells and detectable cytoplasmic staining in negative control (f). MAb4, a minority of cells shows nuclear staining and cytoplasmic staining is not seen in induced cells (g). MAb4, no nuclear neither cytoplasmic staining is detectable in negative control (h). MAb5, a subset of cells with nuclear staining and cytoplasmic staining is not seen in induced cells (i). MAb5, nuclear or cytoplasmic staining is not detectable in negative control (j). MAb6, nuclear and weak cytoplasmic staining is seen in induced cells (k). MAb6, absent nuclear and cytoplasmic staining in negative control (l). PAb1, intense nuclear, nucleolar and cytoplasmic staining in induced cells (m). PAb1, strong nucleolar staining is seen and detectable cytoplasmic staining in negative control (n). PAb2, nuclear and weaker cytoplasmic staining in induced cells (o). PAb2, absent nuclear staining and detectable focal cytoplasmic staining in negative control (p). (Original magnification $\mathrm{x} 400)$.

A

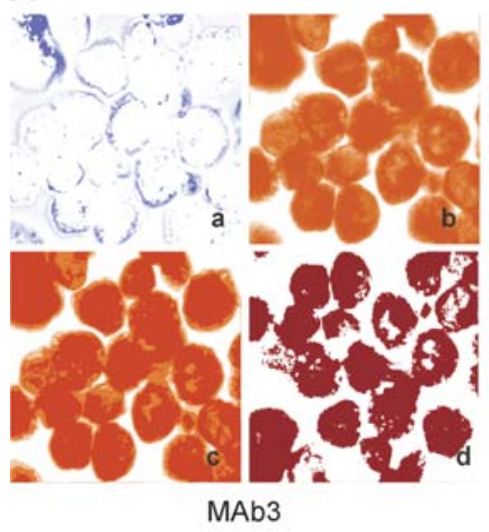

B

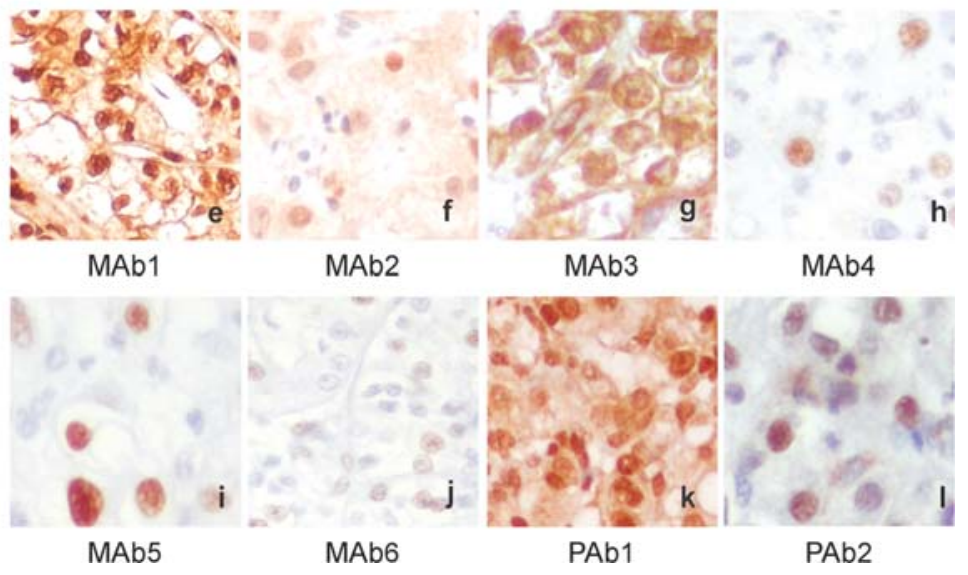

Figure 4. (A) Example of the morphometric approach that is described for MAb3 staining (Fig. 3e and f) in detail in Materials and methods. (a) Haematoxylin stain was separated from the chromogen stain after application of the colour deconvolution plugin. (b and c) Pixels of the chromogen stained image were grouped according to their proximity to the cluster's centroids. A cluster of pixels corresponding to chromogen staining specified at the nuclear area can be discriminated. (d) Color threshold was used to filter out pixels that were of different staining intensity than the nucleus. (B) Examples of the immunostaining in the case of renal cell carcinoma. MAb1, diffuse and intense nuclear staining. Cytoplasmic staining is present (e). MAb2, focal nuclear staining. Weak cytoplasmic staining is detectable (f). MAb3, diffuse and intense nuclear staining. Cytoplasmic staining is present (g). MAb4, focal nuclear staining is seen. Cytoplasmic staining is not present (h). MAb5, focal nuclear staining. Cytoplasmic staining is not present (i). MAb6, nuclear staining is focal and variable. Cytoplasmic staining is not seen (j). PAb1, diffuse and intense nuclear staining. Cytoplasmic staining is prominent (k). PAb2, nuclear staining is convincing. Cytoplasmic staining is absent (1). (Original magnification $\mathrm{x} 400$ ).

DFO treated cells (Fig. 3p). Immunostaining was reproducible in each of the above experiments.
To confirm functional HIF-1 $\alpha$ expression we also analyzed the expression of the known HIF-1 target gene products 
BNIP-3 and VEGF. A polyclonal rabbit antibody for BNIP-3 stained most of the DFO induced HeLa cells. There was predominantly cytoplasmic staining. In addition, there was focal and variable nuclear staining. The control non-induced HeLa cells did not show cytoplasmic or nuclear staining (data not shown). Mab JH121 for VEGF stained $>60 \%$ of the DFO induced HeLa cells. The staining was cytoplasmic and of variable intensity. There was no significant nuclear staining. The control HeLa cells did not show cytoplasmic or nuclear staining (data not shown).

Analysis of tumor tissue samples. Fig. 4 shows immunostaining with various antibodies. Regardless of the tumor origin or type, each antibody maintained its own, somewhat 'idiosyncratic', immunoreactivity pattern, which was similar to that, described previously in the pelleted HeLa cells. Thus, in order to avoid repetitive and beyond scope descriptions, we elected to simplify the results presentation by including comments and comparative illustrations only from the immunostaining of renal cell carcinomas (Figs. 4Be-1).

MAbs 1 (Fig. 4Be), 2 (Fig. 4Bf) and 3 (Fig. 4Bg), and PAb1 (Fig. 4Bk) and 2 (Fig. 4Bl), stained the majority of renal cell carcinoma cells (clear cell type). MAbs 4 (Fig. 4Bh), 5 (Fig. 4Bi) and 6 (Fig. 4Bj) stained a variable subset of renal cell carcinoma cells.

The nuclear (nucleoplasmic) staining was diffusely intense with MAbs 1, 2 and 3 and PAb1 and 2 (Fig. 4Be, f, g, $\mathrm{k}$ and 1$)$. In contrast, the nuclear staining using MAbs 4, 5 and 6 varied (Fig. 4Bh, i and j).

Sporadic nucleolar staining was seen with MAbs 1, 2, 3 and 4 and PAb1 and 2 (Fig. 4Be, f, g, h, k and 1). Nucleolar staining was not seen with MAbs 5 or 6 (Fig. 4Bi and j).

Cytoplasmic staining was seen with MAbs 1, 2 and 3 and PAb1 (Figs. 4Be, f, g and k). Cytoplasmic staining did not hinder the evaluation of nuclear immunoreactivity. In contrast, there was no cytoplasmic staining with MAbs 4,5 or 6 or PAb2 (Fig. 4Bh, i, j and 1).

\section{Discussion}

Immunohistochemistry has been a common method of studying HIF-1 $\alpha$ expression in tumor samples $(3,56)$. Antibody selection has been largely limited to a few commercially available reagents $(28,29,30,31,34,36,48)$ and variation in HIF- $1 \alpha$ immunoreactivity has been documented (3). This variation has been ascribed primarily, albeit conveniently, to alterations of tumor neovascularization and hypoxia. Rarely, attempts have been made to check whether the variation could reflect differential antibody reactivities. Our study, by applying for the first time a systematic approach, demonstrated that HIF-1 $\alpha$ immunostaining might show significant variation that could be 'antibody-dependent'.

Nuclear HIF-1 $\alpha$ immunostaining has been evaluated in most studies because it is well known that the 'active form' of HIF- $1 \alpha$ is localized in the nucleus (6). Two antibodies, MAb3 and PAb1, may show weak nuclear immunostaining even in non-HIF-1 $\alpha$ expressing cellular populations, such as the control HeLa cells used in our study (Fig. 3). One of these antibodies (MAb3) also stained non-HIF-1 $\alpha$ expressing cell nuclei by using immunofluorescence (Fig. 2). Both anti- bodies 'detected' additional proteins (other than HIF-1 $\alpha$ ) in Western blots (Fig. 1). The other six antibodies did not react with nuclei of control non-HIF-1 $\alpha$ expressing HeLa cells. Image analysis showed that by eliminating various aspects of staining we could obtain images that contained only nuclear staining, with no remaining cytoplasmic staining. This method could be helpful for standardizing the evaluation of HIF-1 $\alpha$ immunoreactivity. Similar image analysis applied to MAb3 showed immunostaining of the non-HIF-1 $\alpha$ expressing HeLa cells, and we noted appreciable 'residual' nuclear immunostaining. We were convinced that this staining could not be attributed to confusing, non-specific cytoplasmic immunostaining. Therefore, nuclear immunoreactivity should be evaluated carefully.

MAb1, MAb2, MAb3 and PAb1 stained nucleoli consistently and intensely. PAb2 stained the nucleoli of rare HeLa induced cells. PAb1 was the only one which also stained nucleoli of the control HeLa cells. It is of interest to note that attention to the nucleolar staining was prompted by microscopic examination of immunoreactive HeLa cells, not tissue sections. It is difficult to find examples of distinction between nuclear and nucleolar staining in the pertinent literature. However, the nucleolar localization of HIF-1 $\alpha$ has been established (57). Moreover, nucleolar HIF-1 $\alpha$ is considered to represent an 'inactive' form. Therefore, when using the aforementioned antibodies, an attempted distinction between mere nucleolar staining and generalized nuclear staining seems justifiable and advisable.

The presence and the biological significance of cytoplasmic HIF-1 $\alpha$ staining are controversial. Certain authors have chosen to neglect cytoplasmic immunoreactivity altogether $(34,39,43,48)$. Others mention its presence but opt to ignore its biological significance (30). Other studies have evaluated cytoplasmic immunoreactivity as a genuine element of HIF- $1 \alpha$ expression $(20,31,42,45)$. Recent studies suggest that, at least in cell cultures, transport of HIF-1 $\alpha$ between nucleus and cytoplasm is a highly regulated process, linked to the proliferation state of the cells $(58,59,60)$. It is beyond the scope of our study to investigate the possible biological significance of cytoplasmic HIF- $1 \alpha$ in tissue samples. However, it is worth noting that with one antibody (Mab3), cytoplasmic staining of similar intensity was seen both in HIF-1 $\alpha$ expressing and non-expressing HeLa cells, not only in paraffin-embedded pellets but also by immunofluorescent microscopy (Fig. 2A). Cytoplasmic staining in non-HIF-1 $\alpha$ expressing HeLa cells was noted when using antibodies that detected more than the expected proteins in Western blots (Mab3, Pab1). The only exception to this was our polyclonal antibody, which produced weak cytoplasmic staining despite its specificity verified by Western blotting. Again, this staining was similar in HIF-1 $\alpha$ expressing and non-expressing HeLa cells. Thus, even if HIF-1 $\alpha$ immunoreactivity is detectable in the cytoplasm, it may not represent a component induced by hypoxia and, for that reason, it should not be used as marker of hypoxic tumor cells.

Two monoclonal antibodies (MAbs 4 and 5) stained exclusively the nuclei of HIF-1 $\alpha$ expressing HeLa cells and tissue samples. There was no cytoplasmic or nucleolar staining. In addition, there was no immunoreactivity in nonDFO treated HeLa cells. The corresponding Western blots 
confirmed specificity; however, they stained only a subset of HIF-1 $\alpha$ expressing HeLa cells. Indeed, with one of these two antibodies (MAb4), this subset was small (30-40\%). Similarly, in tumor samples the proportion of immunoreactive nuclei was smaller that that obtained by using the other three antibodies. These findings suggest that for immunohistochemical assessment of HIF- $1 \alpha$ expression, at least two antibodies could be selected. One antibody, preferably polyclonal, can be used to enhance 'sensitivity' and a different one, preferably monoclonal, to 'guard' the immunoassay's specificity.

The future demand for reliable immunoassays and precision-oriented immunohistology will follow the increasing application of novel targeted therapies. HIF-1 $\alpha$ is already seen as a therapeutic target (61). A significant portion of the previous literature may be unsuitable for serving the development of an HIF- $1 \alpha$ immunoassay, and this cannot be attributed solely to the reagents variability. Positive and negative tissue controls, essential components of an immunoassay, appear to have been neglected (62). The option to substitute tissue controls of unknown hypoxic status with well characterized HIF-1 $\alpha$ overexpressing cell lines has not been addressed systematically. Indeed, it has not been applied in most immunohistochemical studies of HIF1 $\alpha$ expression. Our study clearly indicates the usefulness to examine cell-line controls in parallel to tissue samples. Furthermore, future HIF-1 $\alpha$ assays should include methods to estimate the biological significance of a given HIF- $1 \alpha$ overexpression by confirming concurrent overexpression of downstream genomic targets. For that reason, several studies $(20,26,29,48)$ have used the immunohistochemical detection of VEGF with variable success. However, other downstream targets are currently being explored. Their protein products are not secreted and may become stable antigenic targets. Novel findings and our study suggest that BNIP3 expression could be useful (63).

BNIP3 is a pro-apoptotic protein that belongs to the $\mathrm{Bcl}-2$ family (64). Cell death mediated by BNIP3 is independent of caspases and shows several characteristics of necrosis. BNIP3 plays an important role in the hypoxia-induced death of normal and neoplastic cells. BNIP3 is regulated by HIF- $1 \alpha$, which binds to a site on a BNIP3 promoter. Our study represents the first attempt to investigate BNIP3 expression as a marker of hypoxic cells in a wellcharacterized hypoxic cell line model.

The present study is not designed to offer a ready-to-use HIF-1 $\alpha$ immunoassay. However, it demonstrates the task's feasibility and, at the same time, highlights some of the relevant problems. Both are considered as obligatory steps toward further developments in this field of work.

\section{References}

1. Harris AL: Hypoxia, a key regulatory factor in tumour growth. Nat Rev Cancer 2: 38-47, 2002.

2. Maynard MA and Ohh M: The role of hypoxia-inducible factors in cancer. Cell Mol Life Sci 64: 2170-2180, 2007.

3. Mabjeesh NJ and Amir S: Hypoxia-inducible factor (HIF) in human tumorigenesis. Histol Histopathol 22: 559-572, 2007.

4. Maxwell PH: The HIF pathway in cancer. Semin Cell Dev Biol 16: 523-530, 2005.
5. Brahimi-Horn $\mathrm{C}$ and Pouyssegur J: The role of the hypoxiainducible factor in tumor metabolism growth and invasion. Bull Cancer 93: 73-80, 2006.

6. Vaupel P: The role of hypoxia-induced factors in tumor progression. Oncologist 9: 10-17, 2004

7. Semenza GL: HIF-1 and tumor progression: pathophysiology and therapeutics. Trends Mol Med 8: 62-67, 2002.

8. Semenza GL: Hypoxia, clonal selection, and the role of HIF-1 in tumor progression. Crit Rev Biochem Mol Biol 35: 71-103, 2000.

9. Vaupel P, Kallinowski F and Okunieff P: Blood flow, oxygen and nutrient supply, and metabolic microenviroment of human tumors: a review. Cancer Res 49: 6449-6465, 1989.

10. Vaupel P and Harrison L: Tumor hypoxia: causative factors, compensatory mechanisms, and cellular response. Oncologist 9: 4-9, 2004.

11. Maxwell PH, Pugh CW and Ratcliffe PJ: Activation of the HIF pathway in cancer. Curr Opin Genet Dev 11: 293-299, 2001.

12. Ryan HE, Poloni M, McNulty W, Elson D, Gassmann M, Arbeit JM and Johnson RS: Hypoxia-inducible factor-1alpha is a positive factor in solid tumor growth. Cancer Res 60: 4010-4015, 2000.

13. Hokel M and Vaupel P: Tumor hypoxia: definitions and current clinical, biologic, and molecular aspects. J Natl Cancer Inst 93: 266-276, 2001.

14. Semenza GL: Hypoxia-inducible factor 1: control of oxygen homeostasis in health and disease. Pediatr Res 49: 614-617, 2001.

15. Kimbro KS and Simons JW: Hypoxia-inducible factor-1 in human breast and prostate cancer. Endocr Relat Cancer 13: 739-749, 2006.

16. Giatromanolaki A and Harris AL: Tumour hypoxia, hypoxia signaling pathways and hypoxia inducible factor expression in human cancer. Anticancer Res 21: 4317-4324, 2001.

17. Talks KL, Turley H, Gatter KC, Maxwell PH, Pugh CW, Ratcliffe PJ and Harris AL: The expression and distribution of the hypoxia-inducible factors HIF-1alpha and HIF-2alpha in normal human tissues, cancers, and tumor-associated macrophages. Am J Pathol 157: 411-421, 2000.

18. Griffiths EA, Pritchard SA, Valentine HR, et al: Hypoxiainducible factor-1alpha expression in the gastric carcinogenesis sequence and its prognostic role in gastric and gastro-oesophageal adenocarcinomas. Br J Cancer 96: 95-103, 2007.

19. Goonewardene TI, Sowter HM and Harris AL: Hypoxia-induced pathways in breast cancer. Microsc Res Tech 59: 41-48, 2002.

20. Giatromanolaki A, Sivridis E, Simopoulos C, Polychronidis A, Gatter KC, Harris AL and Koukourakis MI: Hypoxia inducible factors 1alpha and 2alpha are associated with VEGF expression and angiogenesis in gallbladder carcinomas. J Surg Oncol 94: 242-247, 2006

21. Koukourakis MI, Giatromanolaki A, Polychronidis A, Simopoulos C, Gatter KC, Harris AL and Sivridis E: Endogenous markers of hypoxia/anaerobic metabolism and anemia in primary colorectal cancer. Cancer Sci 97: 582-588, 2006.

22. Giatromanolaki A, Sivridis E, Fiska A and Koukourakis MI: Hypoxia-inducible factor-2 alpha (HIF-2 alpha) induces angiogenesis in breast carcinomas. Appl Immunohistochem Mol Morphol 14: 78-82, 2006.

23. Giatromanolaki A, Koukourakis MI, Sivridis E, et al: Relation of hypoxia inducible factor 1 alpha and 2alpha in operable non-small cell lung cancer to angiogenic/molecular profile of tumours and survival. Br J Cancer 85: 881-890, 2001.

24. Wei H, Wang $\mathrm{C}$ and Chen L: Proliferating cell nuclear antigen, survivin, and CD34 expressions in pancreatic cancer and their correlation with hypoxia-inducible factor 1 alpha. Pancreas 32: 159-163, 2006

25. Lidgren A, Hedberg Y, Grankvist K, Rasmuson T, Vasko J and Ljungberg B: The expression of hypoxia-inducible factor 1 alpha is a favorable independent prognostic factor in renal cell carcinoma. Clin Cancer Res 11: 1129-1135, 2005.

26. Shi YH, Wang YX, Bingle L, Gong LH, Heng WJ, Li Y and Fang WG: In vitro study of HIF-1 activation and VEGF release by bFGF in the T47D breast cancer cell line under normoxic conditions: involvement of PI-3K/Akt and MEK1/ERK pathways. J Pathol 205: 530-536, 2005.

27. Scarpino S, Cancellario d'Alena F, Di Napoli A, Pasquini A, Marzullo A and Ruco LP: Increased expression of Met protein is associated with up-pegulation of hypoxia inducible factor-1 (HIF-1) in tumour cells in papillary carcinoma of the thyroid. J Pathol 202: 352-358, 2004. 
28. Fillies T, Werkmeister R, van Diest PJ, Brandt B, Joos U and Buerger H: HIF I-alpha overexpression indicates a good prognosis in early stage squamous cell carcinomas of the oral floor. BMC Cancer 5: 84, 2005.

29. Huang GW, Yang LY and Lu WQ: Expression of hypoxiainducible factor 1alpha and vascular endothelial growth factor in hepatocellular carcinoma: impact on neovascularization and survival. World J Gastroenterol 11: 1705-1708, 2005.

30. Osada R, Horiuchi A, Kikuchi N, et al: Expression of hypoxiainducible factor 1alpha, hypoxia-inducible factor 2alpha, and von Hippel-Lindau protein in epithelial ovarian neoplasms and allelic loss of von Hippel-Lindau gene: nuclear expression of hypoxia-inducible factor 1alpha is an independent prognostic factor in ovarian carcinoma. Hum Pathol 38: 1310-1320, 2007.

31. Mizokami K, Kakeji Y, Oda S, Irie K, Yonemura T, Konishi F and Maehara Y: Clinicopathologic significance of hypoxiainducible factor 1alpha overexpression in gastric carcinomas. J Surg Oncol 94: 149-154, 2006.

32. Yoshimura H, Dhar DK, Kohno H, et al: Prognostic impact of hypoxia-inducible factors 1alpha and 2alpha in colorectal cancer patients: correlation with tumor angiogenesis and cyclooxygenase-2 expression. Clin Cancer Res 10: 8554-8560, 2004

33. Wong C, Wellman TL and Lounsbury KM: VEGF and HIF-1 alpha expression are increased in advanced stages of epithelial ovarian cancer. Gynecol Oncol 91: 513-517, 2003.

34. Korkolopoulou P, Perdiki M, Thymara I, et al: Expression of hypoxia-related tissue factors in astrocytic gliomas. A multivariate survival study with emphasis upon carbonic anhydrase IX. Hum Pathol 38: 629-638, 2007.

35. Stewart M, Talks K, Leek R, Turley H, Pezzella F, Harris A and Gatter K: Expression of angiogenic factors and hypoxia inducible factors HIF1, HIF2, and CA IX in non-Hodgkin's lymphoma. Histopathology 40: 253-260, 2002.

36. Nakanishi K, Hiroi S, Tominaga S, et al: Expression of hypoxiainducible factor-1alpha protein predicts survival in patients with transitional cell carcinoma of the upper urinary tract. Clin Cancer Res 11: 2583-2590, 2005.

37. Lidgren A, Hedberg Y, Grankvist K, Rasmuson T, Bergh A and Ljungberg B: Hypoxia-inducible factor 1alpha expression in renal cell carcinoma analyzed by tissue microarray. Eur Urol 50: 1272-1277, 2006.

38. Matsuyama T, Nakanishi K, Hayashi T, et al: Expression of hypoxia-inducible factor-1alpha in esophageal squamous cell carcinoma. Cancer Sci 96: 176-182, 2005.

39. Birner P, Schindl M, Obermair A, Plank C, Breitenecker G and Oberhuber G: Overexpression of hypoxia-inducible factor 1alpha is a marker of an unfavorable prognosis in early-stage invasive cervical cancer. Cancer Res 60: 4693-4696, 2000.

40. Jiang $\mathrm{H}$ and Feng Y: Hypoxia-inducible factor 1 alpha (HIF-1alpha) correlated with tumor growth and apoptosis in ovarian cancer. Int J Gynecol Cancer 16: 405-412, 2006.

41. Boddy JL, Fox SB, Han C, et al: The androgen receptor is significantly associated with vascular endothelial growth factor and hypoxia sensing via hypoxia-inducible factors HIF-1 $\alpha$, HIF-2 $\alpha$, and the prolyl hydroxylases in human prostate cancer. Clin Cancer Res 11: 7658-7663, 2005.

42. Enatsu S, Iwasaki A, Shirakusa T, et al: Expression of hypoxiainducible factor- 1 alpha and its prognostic significance in small-sized adenocarcinomas of the lung. Eur J Cardiothorac Surg 29: 891-895, 2006.

43. Kronblad A, Jirstrom K, Ryden L, Nordenskjold B and Landberg G: Hypoxia inducible factor-1alpha is a prognostic marker in premenopausal patients with intermediate to highly differentiated breast cancer but not a predictive marker to tamoxifen response. Int J Cancer 118: 2609-2616, 2005.

44. Theodoropoulos VE, Lazaris A, Sofras F, et al: Hypoxiainducible factor 1alpha expression correlates with angiogenesis and unfavorable prognosis in bladder cancer. Eur Urol 46: 200-208, 2004
45. Couvelard A, O'Toole D, Leek R, et al: Expression of hypoxiainducible factors is correlated with the presence of a fibrotic focus and angiogenesis in pancreatic ductal adenocarcinomas. Histopathology 46: 668-676, 2005.

46. Kyzas PA, Stefanou D, Batistatou A and Agnantis NJ: Hypoxiainduced tumor angiogenic pathway in head and neck cancer: an in vivo study. Cancer Lett 225: 297-304, 2005.

47. Zhong H, Semenza GL, Simons JW and De Marzo AM: Upregulation of hypoxia-inducible factor 1alpha is an early event in prostate carcinogenesis. Cancer Detect Prev 28: 88-93, 2004

48. Tickoo SK, Alden D, Olgac S, et al: Immunohistochemical expression of hypoxia inducible factor-1alpha and its downstream molecules in sarcomatoid renal cell carcinoma. J Urol 177: 1258-1263, 2007

49. Trastour C, Benizri E, Ettore F, Ramaioli A, Chamorey E, Pouyssegur J and Berra E: HIF-1 alpha and CA IX staining in invasive breast carcinomas: prognosis and treatment outcome. Int J Cancer 120: 1451-1458, 2007.

50. Brat DJ, Castellano-Sanchez AA, Hunter SB, et al: Pseudopalisades in glioblastoma are hypoxic, express extracellular matrix proteases, and are formed by an actively migrating cell population. Cancer Res 64: 920-927, 2004.

51. Birner P, Schindl M, Obermair A, Breitenecker G and Oberhuber G: Expression of hypoxia-inducible factor 1alpha in epithelial ovarian tumors: its impact on prognosis and on response to chemotherapy. Clin Cancer Res 7: 1661-1668, 2001.

52. Mayer A, Wree A, Hockel M, Leo C, Pilch H and Vaupel P: Lack of correlation between expression of HIF-1alpha protein and oxygenation status in identical tissue areas of squamous cell carcinomas of the uterine cervix. Cancer Res 64: 5876-5881, 2004.

53. Lyberopoulou A, Venieris E, Mylonis I, et al: MgcRacGAP interacts with HIF-1 $\alpha$ and regulates its transcriptional activity. Cell Physiol Biochem 20: 995-1006, 2007.

54. Abramoff MD, Magelhaes PJ and Ram SJ: Image processing with ImageJ. Biophotonics International 11: 36-42, 2004

55. Triantafyllou A, Liakos P, Tsakalof A, Georgatsou E, Simos G and Bonanou S: Cobalt induces HIF-1alpha in HeLa cells by an iron-independent, but ROS-, PI-3K- and MAPK-dependent mechanism. Free Radic Res 40: 847-856, 2006.

56. Zhong H, De Marzo AM, Laughner E, et al: Overexpression of hypoxia-inducible factor 1alpha in common human cancers and their metastases. Cancer Res 59: 5830-5835, 1999.

57. Fatyol K and Szalay A: The p14 ${ }^{\mathrm{ARF}}$ tumor suppressor protein facilitates nucleolar sequestration of hypoxia-inducible factor1alpha (HIF-1alpha) and inhibits HIF-1-mediated transcription. J Biol Chem 276: 28421-28429, 2001.

58. Mylonis I, Chachami G, Samiotaki M, et al: Identification of MAPK phosphorylation sites and their role in the localization and activity of Hypoxia-inducible Factor-1 $\alpha$. J Biol Chem 281: 33095-33106, 2006.

59. Triantafyllou A, Mylonis I, Simos G, Bonanou S and Tsakalof A: Flavonoids induce HIF-1alpha but impair its nuclear accumulation and activity. Free Radic Biol Med 44: 657-670, 2008.

60. Mylonis I, Chachami G, Paraskeva E and Simos G: Atypical CRM1-dependent nuclear export signal mediates regulation of Hypoxia-inducible Factor- $1 \alpha$ by MAPK. J Biol Chem 283: 27620-27627, 2008

61. Melillo G: Targeting hypoxia cell signaling for cancer therapy. Cancer Metastasis Rev 26: 341-352, 2007.

62. Cregger M, Berger AJ and Rimm DL: Immunohistochemistry and quantitative analysis of protein expression. Arch Pathol Lab Med 130: 1026-1030, 2006.

63. Lee H and Paik SG: Regulation of BNIP3 in normal and cancer cells. Mol Cells 21: 1-6, 2006.

64. Marsden VS and Strasser A: Control of apoptosis in the immune system: Bcl-2, BH3-only proteins and more. Annu Rev Immunol 21: 71-105, 2003. 